\title{
EL RELIEVE DE JORGE OTEIZA EN LA PLANTA BAJA DE SU VIVIENDA EN IRÚN: ESCULTURA, ARQUITECTURA Y ESPACIO PÚBLICO
}

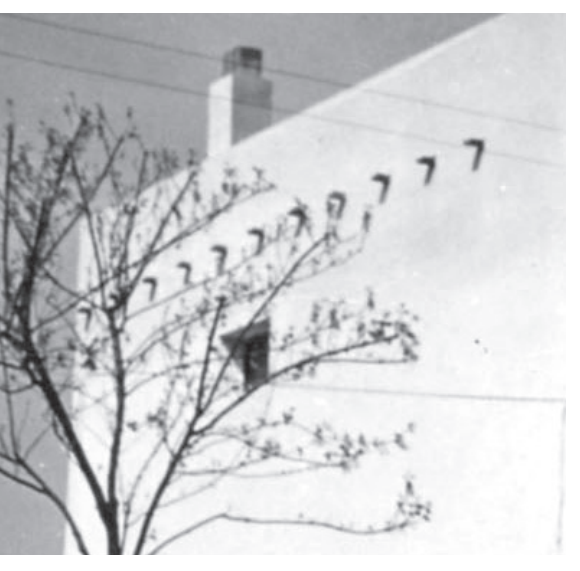

\author{
Emma López-Bahut
}

The Jorge Oteiza relief in the ground floor of his dwelling house in Irü: architecture, sculpture and public space

\author{
Boletín Académico. Revista de investigación y arquitectura contemporánea \\ Escuela Técnica Superior de Arquitectura. Universidade da Coruña \\ elSSN 2173-6723 \\ www.boletinacademico.com \\ Número 4 (2014) \\ Páginas 33-42 \\ Fecha de recepción 30.10.2013 \\ Fecha de aceptación 13.01.2014

\section{Resumen}

Gracias al hallazgo de nuevo material documental, se demuestra la autoría de Jorge Oteiza del relieve en el forjado superior de la planta baja de su vivienda en Irún, hasta ahora desconocido. A partir de esta intervención, se profundiza en la relación del escultor con el mundo arquitectónico en tres aspectos: la aplicación en la arquitectura de conceptos espaciales que descubre previamente en la escultura; la propuesta concreta de un modo de integración del arte y la arquitectura; su consideración como el primer trabajo en el que Oteiza plantea una relación directa con el espacio urbano y su habitante.

\begin{abstract}
Due to the finding of new documentary material, I prove the authorship of Jorge Oteiza of the relief located in the upper slab of the ground floor of his house in Irún, which was unknown until now. I delve into the relation of the sculptor with the architecture in three aspects: the application of spatial concepts that has previously discovered in the sculpture; the specific proposal of a way for joining art and architecture; and I can state that this is the first work where Oteiza puts forward a direct relation with the urban space and its inhabitant.
\end{abstract}

\section{Palabras clave}

Arquitectura, escultura, espacio, Jorge Oteiza, País Vasco

\section{Keywords}

Architecture, Sculpture, Space, Jorge Oteiza, Basque country 

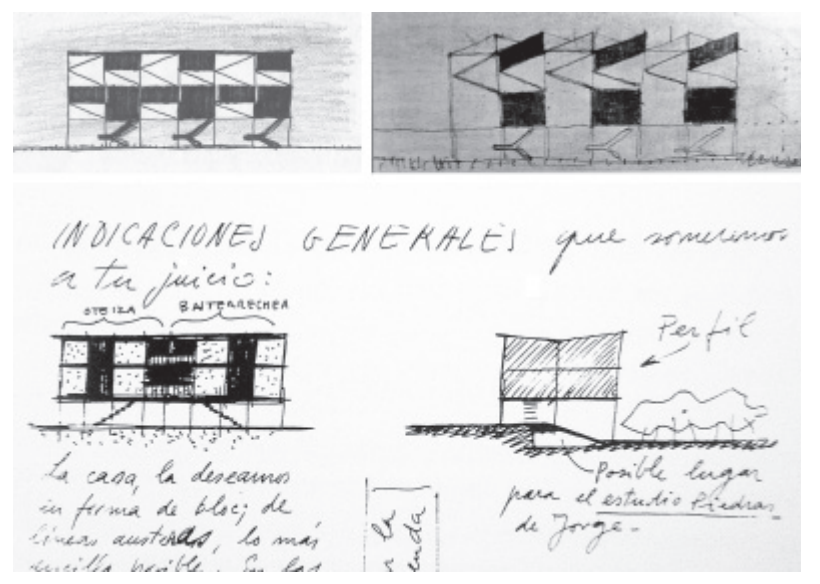

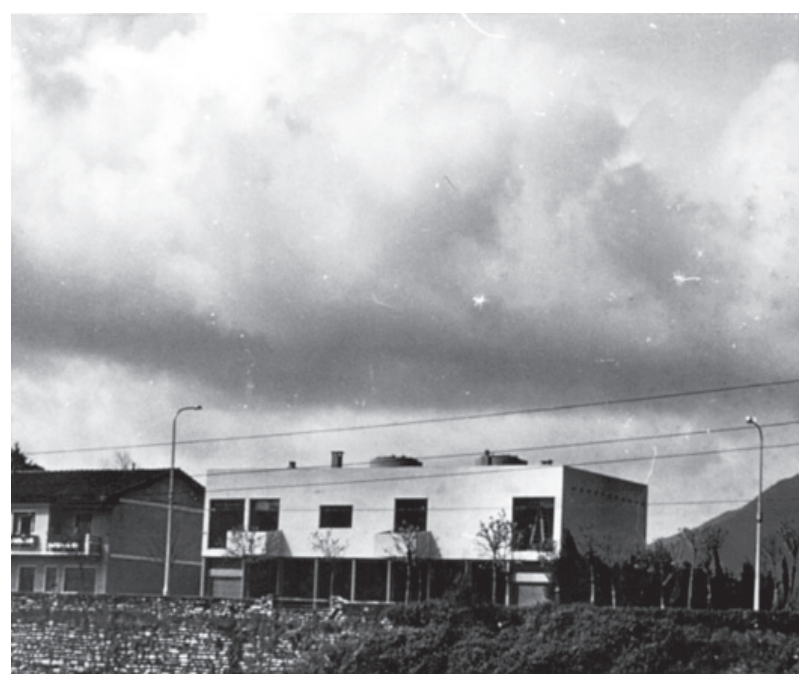

01 Francisco Javier Sáenz de Oiza, viviendas para Oteiza, Basterrechea y Oiza, Irún (Guipúzcoa), 1955. Arriba: croquis del alzado posterior. Abajo: croquis del alzado principal y lateral; sin fecha.

$\mathbf{0 2}$ Luis Vallet, viviendas para Oteiza y Basterrechea, Irún (Guipúzcoa), 1958. Esta fotografía ha sido publicada retocada, eliminando la vivienda vecina para potenciar la idea de la casa como objeto autónomo.

En la década de los cincuenta, la colaboración entre arquitectos y artistas fue un hecho fundamental que contribuyó al avance de la arquitectura española, que había sido interrumpido por la Guerra Civil y la autarquía de los años cuarenta ${ }^{1}$. En los intercambios entre ambas disciplinas, el escultor Jorge Oteiza fue una figura de referencia, pues trabajó con diferentes arquitectos en obras clave en la historia de la arquitectura espańola ${ }^{2}$. Al mismo tiempo, entre 1948 y 1960, desarrolló su máxima experimentación artística, situándose internacionalmente como uno de los mejores artistas, gracias al premio obtenido en 1957 en la IV Bienal de São Paulo ${ }^{3}$. Mientras trabajaba en las piezas con las que triunfaría en la Bienal, estaba finalizando la construcción de su vivienda en Irún, que significaría su regreso al País Vasco a principios de 1958, y en la que viviría hasta 1976. M. Rowell considera que el entorno espacial determinó el carácter artístico de Oteiza ${ }^{4}$, y por ello este retorno a su origen es tremendamente significativo y con consecuencias en su escultura y pensamiento. Además, así como la casa es la escala arquitectónica en la que los arquitectos se sienten más cómodos para experimentar ${ }^{5}$, así la propia vivienda significa abrir un campo de pruebas con una infinita libertad. Por ello, cobra especial importancia la intervención de Oteiza en su vivienda, en la que experimentará su propio planteamiento sobre la integración de la escultura en la arquitectura6.

Entre los años 1954 y 1958 se desarrolló el proyecto de dos viviendas, con sus respectivos talleres, para Oteiza y Néstor Basterrechea. En el proceso intervinieron los arquitectos Francisco Javier Sáenz de Oiza y Luis Vallet de Montano, colaborando también los dos artistas. Durante la construcción, Oteiza realizó un relieve en el forjado superior de la planta baja del edificio. Esta intervención resulta fundamental porque, además de ser un ejemplo del tipo de integración de la escultura y la arquitectura que proponía, supuso un cambio en el pensamiento de Oteiza, ya que no se limitó a colocar su obra en una arquitectura dada, sino que tuvo una intención arquitectónica-urbana.

Conviene diferenciar las intervenciones de Oteiza en fachadas con un carácter más decorativo de aquéllas en las que tiene en cuenta el espacio urbano. En las primeras, el escultor actúa en la piel del edificio sin la intención de interferir en el espacio urbano, como sucede en el Instituto de Inseminación Artificial Ganadera en Madrid (1955). Por el contrario, en las segundas toma importancia el lugar en el que se ubican y se hace participar activamente al habitante. Son trabajos realizados bajo conceptos descubiertos en sus esculturas, más espaciales y menos planos, y en los que la luz adquiere importancia. El relieve de las viviendas de Irún es un ejemplo de este tipo de intervenciones.

Se trata de una obra de Oteiza de la que no se tenía referencia hasta este momento ${ }^{7}$. Por ello, esta investigación tiene por objeto sacar a la luz esta intervención, demostrar su autoría, y poner de manifiesto su importancia dentro del pensamiento oteiziano sobre lo arquitectónico en varios aspectos: la aplicación de conceptos escultóricos a los edificios, las relaciones que se buscan con el espacio urbano, y la síntesis del arte en la arquitectura. 

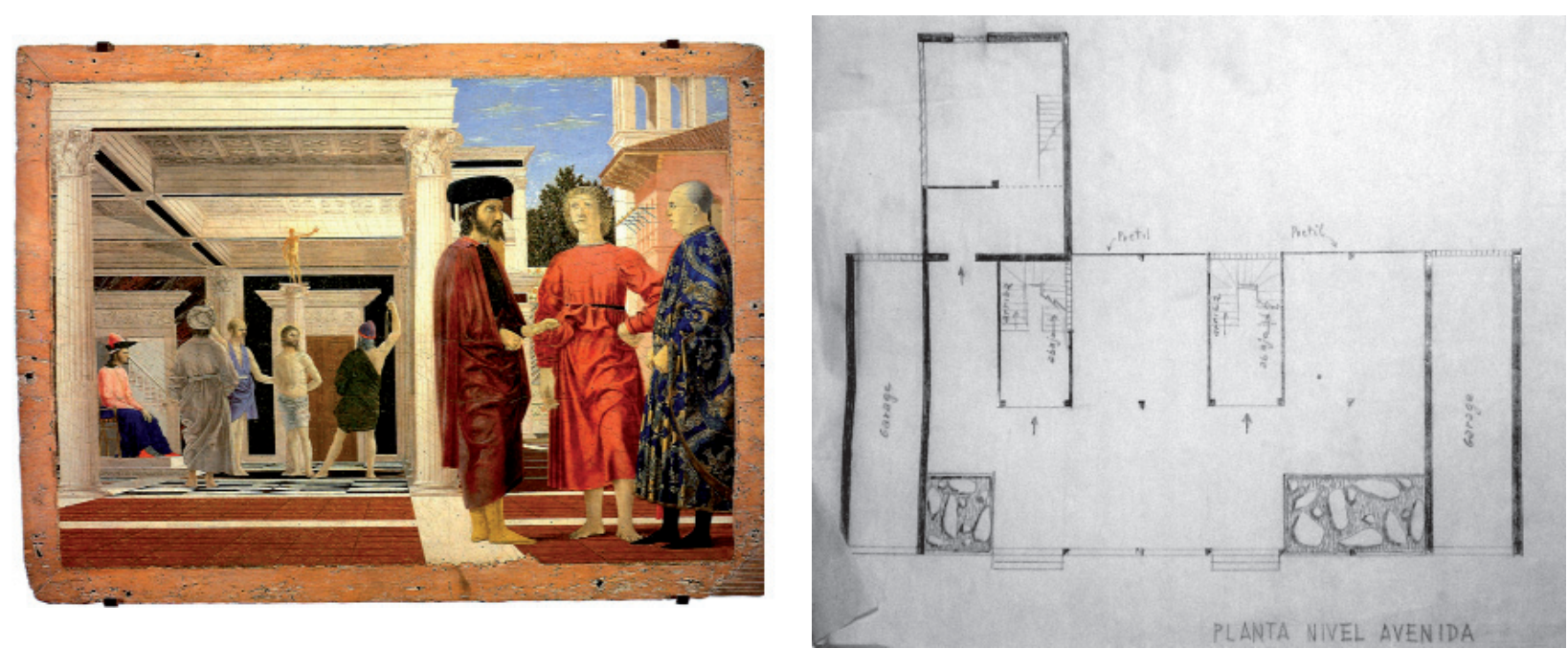

03 Piero de la Francesca, La Flagelación de Cristo, Galleria Nazionale delle Marche (Urbino, Italia), 1444/69.

04 Luis Vallet, viviendas para Oteiza y Basterrechea, Irún (Guipúzcoa); versión del proyecto desarrollado entre noviembre de 1956 y febrero de 1957; plano de la planta baja

Se ha realizado una intensa exploración documental en el archivo de Oteiza y en el archivo personal de Luis Vallet, ordenando cronológicamente y analizando los croquis, planos y la correspondencia mantenida entre el arquitecto y los artistas ${ }^{8}$. A raíz de los resultados, se ha reconstruido el desarrollo del proyecto, desde las primeras ideas hasta su construcción, en el que se diferencian catorce versiones. En cada una de ellas se ha conseguido determinar quien propone los cambios y toma las principales decisiones del diseño, unas veces el arquitecto y otras los artistas. Durante cuatro años se sucedieron diferentes propuestas, sintetizadas en tres fases': un primer momento de ideación, con la participación principalmente de Oteiza y Sáenz de Oiza, que finaliza cuando el arquitecto abandona el proyecto a finales de 1955; una segunda fase en la que Vallet desarrolla la propuesta, con aportaciones de los dos artistas, hasta llegar a un proyecto visado muy alejado del que se materializará; y por último, la redefinición del proyecto en la ejecución, en la que Oteiza tiene una clara participación.

Fruto de este análisis y sistematización es el hallazgo de la única obra de arte en el edifico, objeto de este estudio. Sobre el relieve en la planta baja se analizan a continuación los tres aspectos que fundamentan la intervención de Oteiza. El primero, las cualidades del espacio en el que interviene, la planta baja abierta a la calle y al jardín posterior. Sáenz de Oiza es el que imagina este espacio, que se desarrolla en todo el proceso proyectual de la mano de Luis Vallet hasta llegar a ser construido. El segundo punto es la intervención escultórica en sí y sus relaciones y diferencias con otros trabajos murales realizados en el mismo periodo. El tercer aspecto es cómo aplica Oteiza lo descubierto en la escultura a un espacio arquitectónico concreto que se relaciona de manera directa con un espacio urbano.

\section{CARACTERÍSTICAS ESPACIALES DE LA PLANTA BAJA}

El lugar elegido para las casas se ubica en las afueras de Irún, en la vía que conectaba con la frontera francesa. Un solar rectangular, de $30 \mathrm{~m}$. de frente y 29 $\mathrm{m}$. de profundidad, con pendiente perpendicular a la calle que caía hacia un pinar en la parte de atrás. Inicialmente el proyecto consistía en tres viviendas: la de Oteiza, la Basterrechea y la de Sáenz de Oiza, quien las proyecta; ya estaban en contacto con Vallet, quien llevaría en Irún su construcción. Pero, en la primavera de 1956, Sáenz de Oiza cambia de opinión y abandona el proyecto, y es Vallet el que diseña y ejecuta las viviendas.

La idea de elevar la casa respecto a la calle es una de las decisiones que aparece en los croquis de Sáenz de Oiza, y que se confirma en las indicaciones dibujadas que Basterrechea y Oteiza envían a Vallet, cuando éste se hace cargo del proyecto (Fig. 01). En la planta alta se ubican las viviendas $y$, aprovechando la diferencia de cota, el estudio de Oteiza se sitúa por debajo del nivel de la calle. Entre las características que le piden para la casa, escriben: «Deberá ser sobreelevada para salvar el nivel de la carretera y ampliar vistas» ${ }^{10}$. 


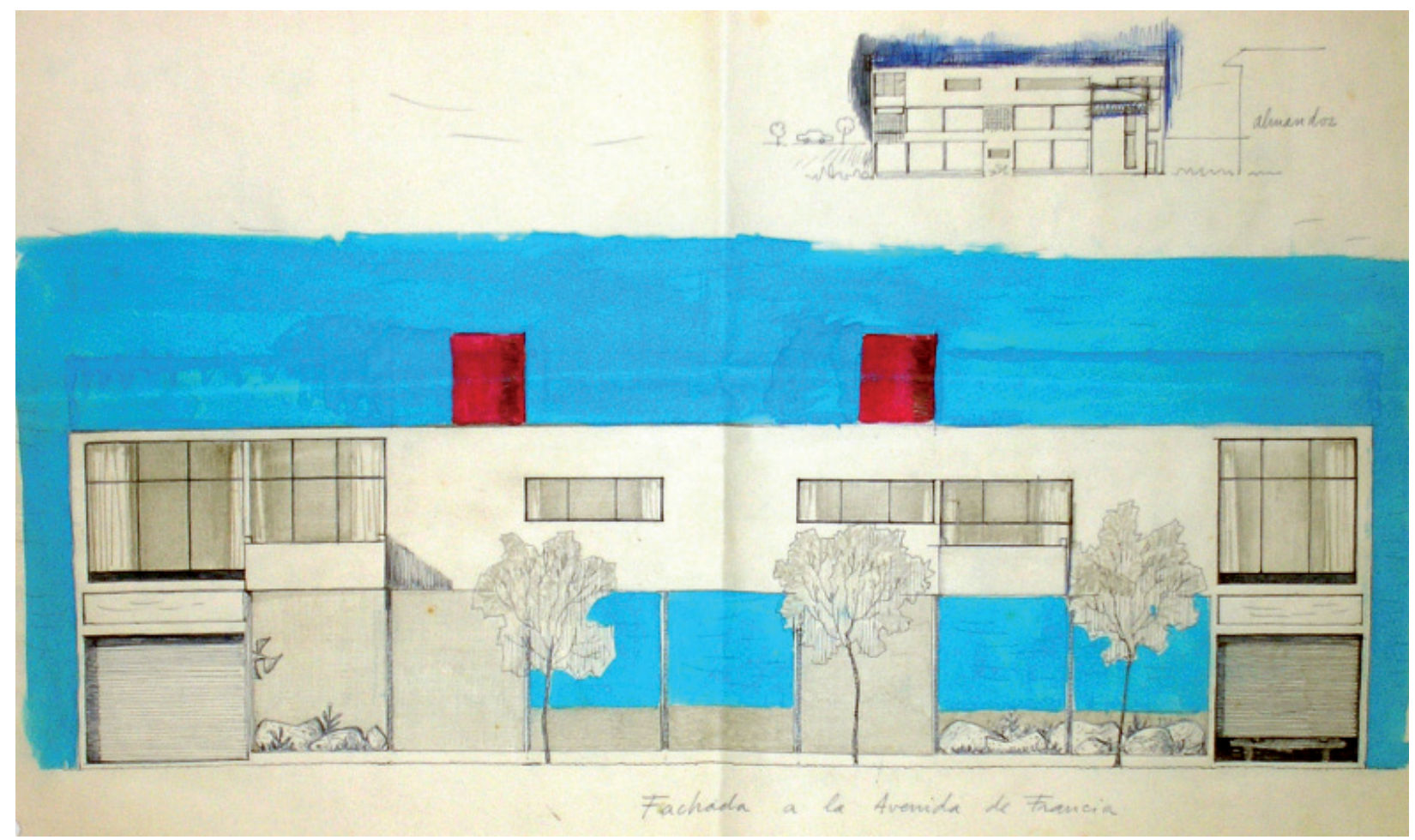

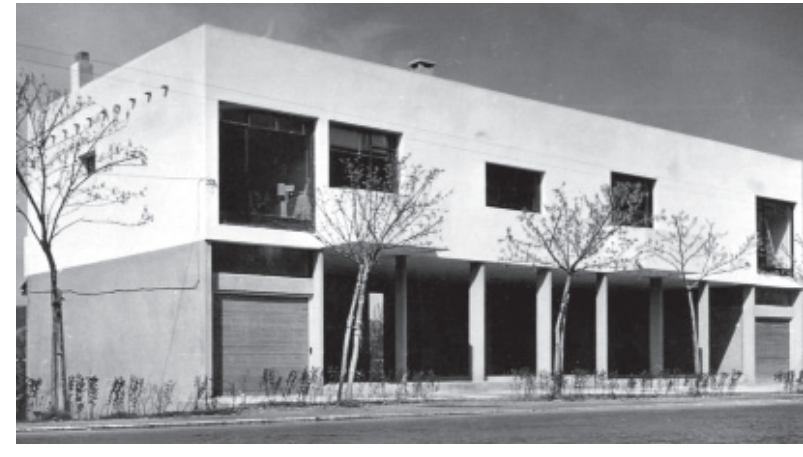

05 Luis Vallet, viviendas para Oteiza y Basterrechea, versión del proyecto desarrollado en abril de 1957; plano del alzado principal.

06 Fotografía de las viviendas, 1958.

07 Itziar Carreño y Néstor Basterrechea, junto con otras personas, frente a las viviendas de Irún, sin fecha.

08 Versión del proyecto desarrollado en junio de 1956; plano de alzado principal.
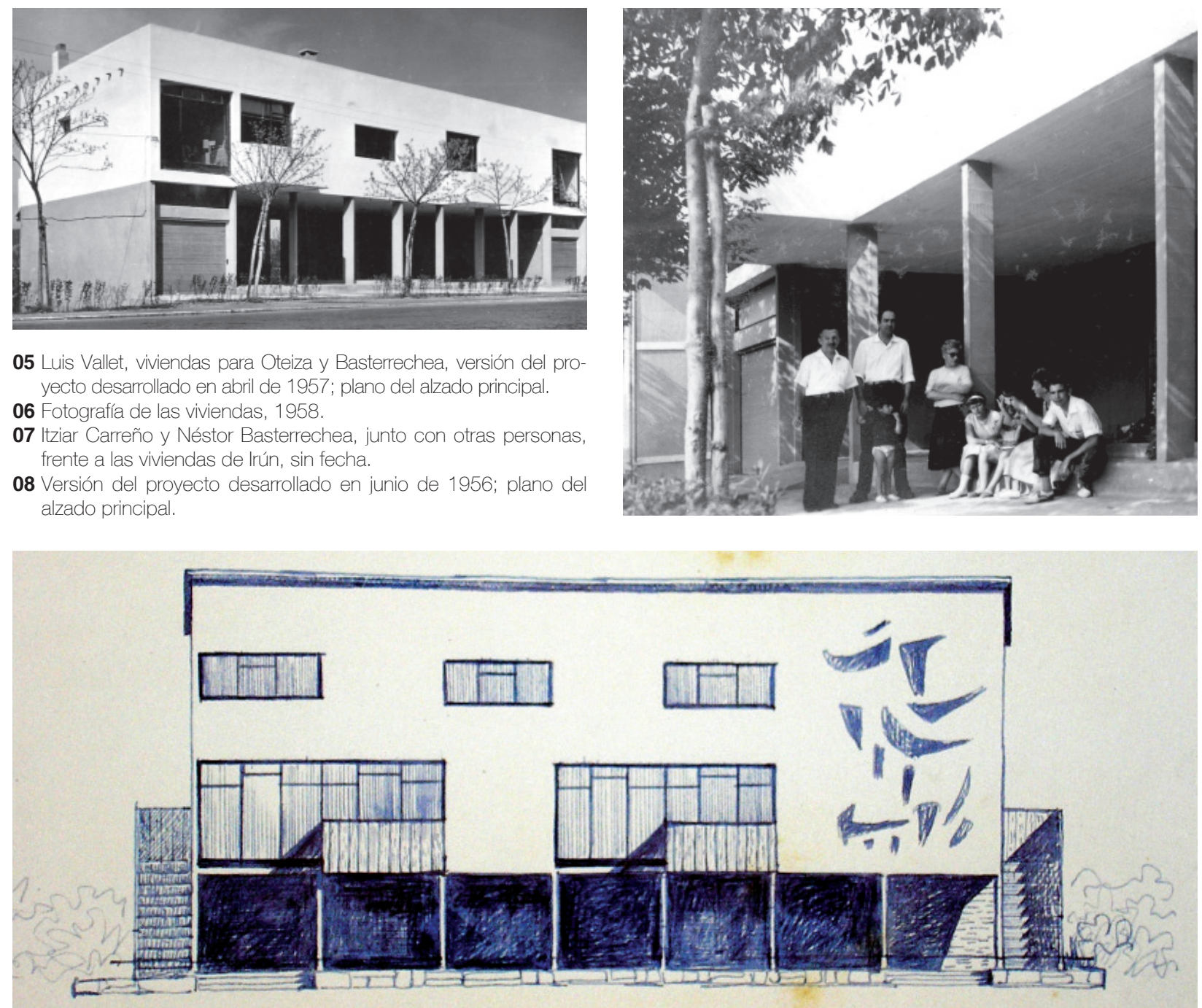


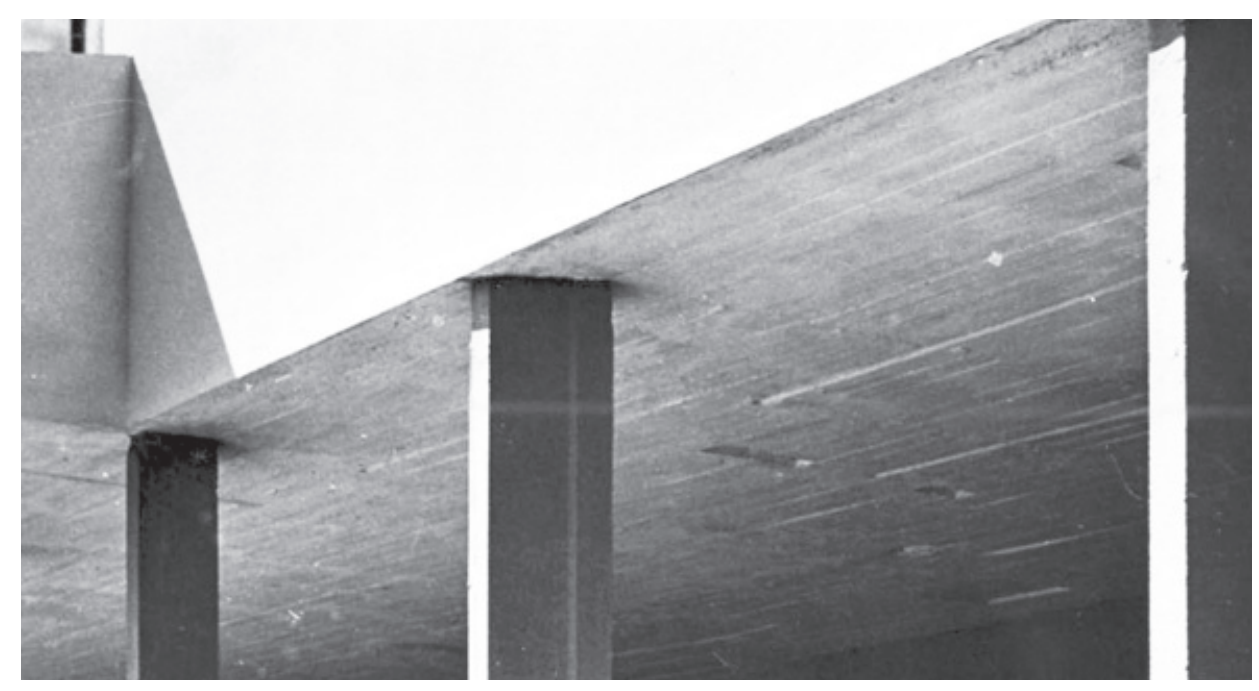

09 Viviendas para Oteiza y Basterrechea; detalle del relieve de la planta baja, visión desde la acera.

Al situar las viviendas sobre pilares se genera un espacio en planta baja que se abre a la calle y se prolonga visualmente hasta el jardín y el pinar. Este espacio cubierto se mantiene a lo largo de todo el proyecto sin ninguna función específica. En ningún plano del proceso se rotula su uso; ni siquiera se piensa en cerrar o acristalar. Sin embargo, éste es el espacio más singular de las casas, tanto por su relación directa con la calle y el paisaje como por ser en el que Oteiza interviene escultóricamente. Un espacio que pertenece a las viviendas pero que, al mismo tiempo, forma parte de la avenida, del espacio urbano, y mira al paisaje lejano (Fig. 02).

Elevar las viviendas es una decisión que se hereda de las propuestas de Sáenz de Oiza, y por ello conviene repasar su pensamiento e iconografía. Al hablar de la Capilla en el Camino de Santiago (1954), que había realizado con Oteiza y Luis Romaní, señalaba como referencia el cuadro de Piero de la Francesca La flagelación de Cristo (Fig. 03) ${ }^{11}$, indicando que también era el favorito de Le Corbusier ${ }^{12}$. Esta idea, que Sáenz de Oiza no pudo desarrollar en la Capilla, fue aplicada a sus propias viviendas en Irún. El cuadro representa un espacio con doble carácter, donde el espectador no sabe si la escena se desarrolla en el exterior o en el interior. Este espacio dual se encuentra en la planta baja de las viviendas de Irún. Y como en el cuadro, los relieves del techo son los que Oteiza realizará.

Finalmente este gran espacio $(23,5 \times 10 \mathrm{~m}$.) queda vacío en planta baja (Fig. 04). Por su profundidad, sería una zona relativamente en penumbra aunque se llegaría a ver el jardín posterior. Los módulos extremos se destinan a garajes y en ellos se ubican las cajas de escaleras de acceso a cada vivienda, cerradas con pavés para que parecieran menos masivas desde el exterior. La colocación del estudio de Oteiza cierra parte de la comunicación visual con el jardín. Al mismo tiempo, los pilares más expuestos a la calle tienen forma trapezoidal, de tal modo que parecen de menor tamaño, más finos y esbeltos. En los alzados a color (Fig. 05), Vallet los dibujaba exageradamente esbeltos, con la mínima presencia, confundiéndose casi con los troncos de los árboles de delante y, así, potenciando la comunicación entre la calle y el paisaje lejano.

Una conversación mantenida con los nietos de Vallet me dio la clave para poder intuir el uso de ese espacio. Ellos denominan al edificio como "las casas-museo»" ${ }^{13}$ y no casa-taller o casas estudio como se nombran en las publicaciones sobre el tema. El único espacio de todo el proyecto que serviría como lugar de exposición sería la planta baja. Con el paso del tiempo, además, fue empleado como un escenario público donde Oteiza y Basterrechea se fotografiaron con aquellos personajes que les visitan, y en ocasiones, Oteiza también lo utilizó para fotografiar sus propias esculturas (Fig. 06-07).

\section{EL RELIEVE DE OTEIZA}

Definida la principal característica de la planta baja - un espacio que pertenece tanto a las casas como a la calle y abierto al paisaje—, su interés aumenta al ser donde Oteiza interviene con un trabajo escultórico. 

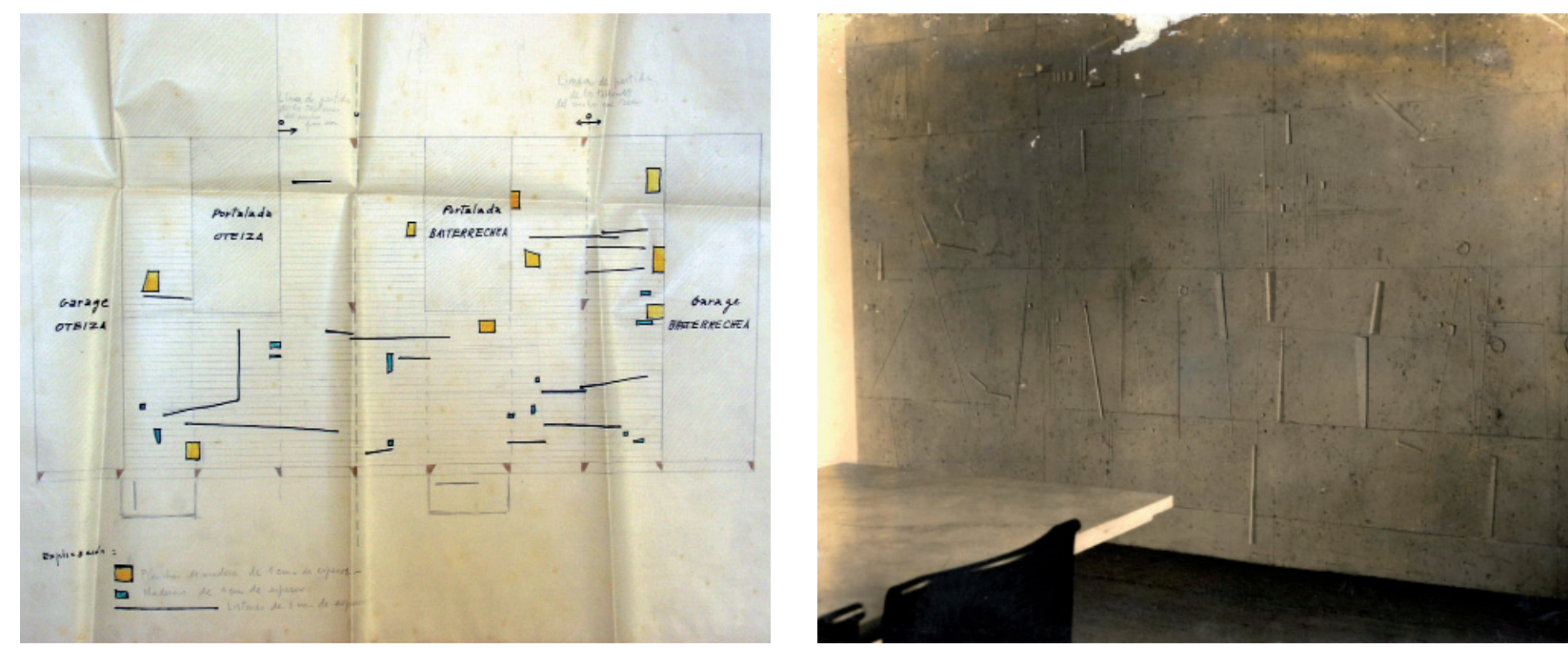

10 Luis Vallet, viviendas para Oteiza y Basterrechea, sin fecha; plano de planta de techos de la planta baja. 11 Jorge Oteiza, Homenaje a Bach, Madrid, 1956.

En el desarrollo del proyecto existen varios intentos de colocar pequeños murales incrustados en fachadas o en las cajas de escalera en planta baja. Estas intervenciones se ligan casi siempre a la parte del edificio de Basterrechea, con un claro carácter decorativo (Fig. 08). Finalmente, ninguno de estos murales se llevó a cabo.

En el detalle de algunas fotografías podemos apreciar el trabajo en el forjado en la planta baja (Fig. 09). En las imágenes de las viviendas recién acabadas, se comprueba que este trabajo fue finalmente realizado y, observando detenidamente, se puede afirmar que se trata de un relieve a base de incisiones o grabaciones sobre el hormigón ${ }^{14}$. Pero, debido a las condiciones actuales del edificio, cuya planta baja ha sido totalmente cerrada, no se ha podido comprobar in situ si el relieve se conserva todavía.

La clave fue el plano del forjado de la planta baja y la carta que Vallet escribe a Oteiza anunciando su realización ${ }^{15}$. En este plano se marcan elementos de madera con diferentes formas. En las fotografías apreciamos que no se dejaron incrustados en el techo, sobresaliendo (Fig. 10). Sirvieron como un encofrado del relieve, que se retiraron cuando el hormigón había fraguado, quedando marcados en el forjado de hormigón, con profundidad, como una inscripción.

La autoría de este relieve la atribuyo a Oteiza por tres razones. En primer lugar, porque la posibilidad de que lo realizase Basterrechea, quien a lo largo del diseño propone piezas en fachada, queda descartada al analizar las propuestas artísticas que en ese momen- to estaba realizando en una línea más expresionista, alejadas de la composición del relieve ${ }^{16}$. El segundo argumento es la carta que le envía Vallet a Oteiza informándole que ya se ha construido el forjado de la planta baja y que "han salido perfectos los dibujos del techo» ${ }^{17}$. También podría pensarse que el arquitecto hubiera realizado este trabajo, pero, tras haber estudiado el desarrollo del proyecto y cómo se toman las decisiones, ninguno de los dos artistas dejaría en manos del arquitecto la realización de la única obra de arte integrada en la arquitectura ${ }^{18}$. Además, y como ejemplo de su implicación en la toma de decisiones sobre cuestiones tanto artísticas como escultóricas, en esa misma carta Vallet cede a Oteiza la elección de la forma de la capilla del Memorial al padre Donosti en Aguiña, proyecto en el estaban trabajando al mismo tiempo ${ }^{19}$. La última razón la aporta el análisis de dos trabajos murales que Oteiza estaba realizando o acababa de concluir en abril de 1957: Homenaje a Bach (Fig. 11) y Formas lentas cayéndose y levantándose en el laberinto (Fig. 12). También se organizan sobre un plano pétreo, que marca un ritmo subyacente propio del material, en el que aparecen elementos rectilíneos y trapezoidales y —en el caso del segundo- algunos curvilíneos. El resultado del forjado de Irún se asemeja a Homenaje a Bach en el modo de realización, a base de incisiones en un material pétreo. En el primero, mediante el encofrado, y en el segundo, tallando directamente la piedra. Las tres obras tienen en común que el muro como tal empieza a vaciarse, pesando más los espacios vacíos que la materia formal, fruto de los trabajos que Oteiza estaba realizando con las maquetas de la «Pared-luz». 


\section{LA PARED-LUZ APLICADA A LA ARQUITECTURA}

A finales de 1956, Oteiza elabora unas maquetas de vidrio que denomina «Pared-luz», y que consisten en una superposición de vidrios, planos o curvos, en los que se intercalan elementos formales planos. Bajo la acción de la luz, las formas cambian e interactúan entre ellas y con sus sombras, el espacio se hace evidente ${ }^{20}$. Oteiza bautiza estos elementos mínimos trapezoidales planas como «Unidades Malevich» que, puestas en relación, son capaces de definir espacios (Fig. 13). Las conclusiones de la «Pared-luz» las aplica a sus esculturas y, del mismo modo, a los trabajos murales que en ese momento estaba realizando, obras en las que la masa del muro desaparece y las relaciones forma y espacio se invierten, empleando mínima materia formal (elementos en relieve o incisiones) y el máximo vacío mural.

La posición horizontal del relieve de las viviendas de Irún se relaciona con los experimentos de la «Paredluz»: se trabaja en horizontal, con unidades livianas (líneas y trapecios) que adquieren carácter hiperespacial gracias a las infinitas posiciones del observador, en la planta baja o en el espacio urbano, y a los cambios naturales en la luz y sus consecuentes sombras. El espectador empieza a considerarse como habitante.

En «Propósito experimental 1956-1957»" , Oteiza recupera la idea de que la intervención en una obra mural de carácter público debe ser realizada considerando el espacio en el que se inserta, «el espacio anterior al Muro", y, como consecuencia, el espectador debe ser incluido en esa obra. El mural no debe realizarse desde la exigencia del movimiento del espectador como Oteiza atribuye al muralismo mexicano de José Clemente Orozco o de Diego Rivera- es decir, concibiendo el mural como una sucesión de imágenes/ escenas que el espectador percibirá según se desplace frente a él. Por el contrario, Oteiza defiende que la persona es el centro del mural y, por su movimiento, se generan múltiples posibilidades. El artista debe crear plásticamente el Muro desde esta nueva dimensión, que introduce el espectador. Además de ese «espacio anterior al Muro", la planta baja del edificio, hay que incluir en su creación al espectador, que surge, al igual que el espacio, con carácter dual, pues puede ser habitante de la vivienda o del espacio urbano. El relieve del techo se concibe como la suma de infinitos conjuntos plásticos: infinitos, como los puntos de vista que las personas puedan tener.
Si Oteiza hubiera trabajado en el plano vertical de la fachada - como alguna de las propuestas de Basterrechea-su intervención apenas hubiera sido advertida por las personas que caminasen por la misma acera de las casas, y solo podría ser percibida por aquéllas que se encontrasen a distancia suficiente por la otra acera o circulando en coche. El habitante de la vivienda también quedaría al margen de su visión. Por lo tanto, para agrupar los máximos puntos de vista del espectador y, de este modo, obtener las máximas capacidades de su trabajo con el Muro, Oteiza elige el plano horizontal para trabajar. Así, los dos posibles espectadores - el habitante y el ciudadano- quedan incorporados a esta intervención (Fig. 14).

\section{CONCLUSIONES}

Se ha demostrado la realización por Oteiza del relieve en el forjado superior de la planta baja. De forma semejante a lo que observó en sus experimentos con la «Pared-luz», en el relieve emplea mínimas formas, teniendo en cuenta las variaciones de luz y los infinitos puntos de vista del habitante y del ciudadano. Todo ello hace que el forjado, estéticamente, comience a perder presencia, a desmaterializarse. La planta baja se abre a la calle y al jardín posterior, y con esta actuación, el techo nos parece menos masivo. Un espacio que podría suponerse destinado a la exposición de las obras de los artistas. Semejante al de La flagelación de Cristo, tiene un carácter dual en muchos aspectos: interior-exterior, privado-público, casa-calle, techado-abierto, urbanonatural. El carácter de esta planta está en relación directa con el espacio urbano con el que se relaciona de manera inmediata, visual y físicamente, comunicándolo con el jardín de atrás y el paisaje natural ${ }^{22}$.

Durante todo el desarrollo del diseño y construcción, la planta baja estuvo prácticamente vacía y sin un uso específico. Tras el descubrimiento del relieve en el forjado superior, ese vacío cobra otro significado porque ha sido obtenido desde la estrategia - tanto arquitectónica como escultórica- de lo que Oteiza denominaba «desocupación formal del espacio» ${ }^{23}$. En este mismo sentido, y de manera posterior a la realización del relieve, se entiende su decisión de pintar toda la parte inferior del edificio de color gris, frente al blanco de la parte superior (Fig. 02 y 06). El gris es definido por el escultor no por su valor estético, sino por su carácter espacial. Y pintar toda la planta baja de gris tiene la intención de espaciarla, de desocuparla y así potenciar la flotabilidad de la parte superior, retomando la idea de las primeras propuestas de 

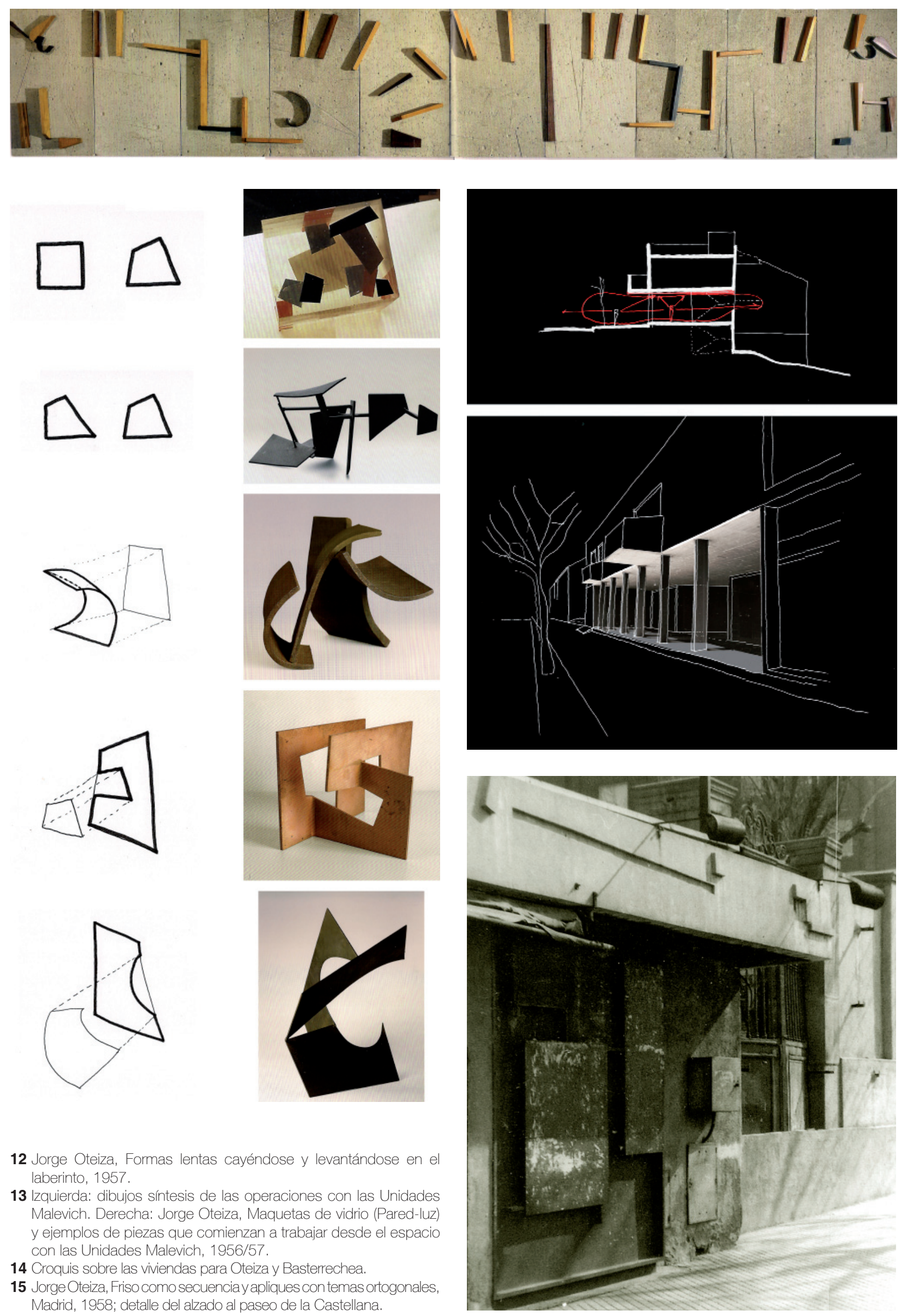

12 Jorge Oteiza, Formas lentas cayéndose y levantándose en e laberinto, 1957.

13 Izquierda: dibujos síntesis de las operaciones con las Unidades Malevich. Derecha: Jorge Oteiza, Maquetas de vidrio (Pared-luz) y ejemplos de piezas que comienzan a trabajar desde el espacio con las Unidades Malevich, 1956/57.

14 Croquis sobre las viviendas para Oteiza y Basterrechea.

15 Jorge Oteiza, Friso como secuenciay apliques contemas ortogonales, Madrid, 1958; detalle del alzado al paseo de la Castellana. 
Sáenz de Oiza. Al mismo tiempo que se terminaban las obras de las viviendas, Oteiza escribe «Propósito Experimental Irún $»^{24}$, en el que define relaciones entre arte y arquitectura que se intuyen ya en la intervención en la planta baja y la inclusión del habitante en ellas: «Me instalo en la función de la arquitectura. La pintura de caballete ha saltado al muro y lo ha desocupado. El color del muro es gris. La habitación está vacía y entra el habitante. (...) Aquí es donde en el espacio de la arquitectura y desde ella, puede surgir la obra de arte, es decir, donde un sitio del espacio arquitectónico —en 2 o 3 dimensiones- puede convertirse en escultura o pintura» ${ }^{25}$.

Como conclusión de lo expuesto, podemos afirmar que los dibujos en el techo de la planta baja de las viviendas de Irún son el primer trabajo en el que Oteiza desarrolla el concepto «Pared-luz» integrado en la arquitectura y que, además, lo elabora en relación con el espacio urbano teniendo en cuanta al habitante.

Tras su experiencia en el relieve de Irún, Oteiza realiza el friso para el hotel Fénix en Madrid (1958), otra intervención en relación a un espacio urbano (Fig. 15). Actúa en dos escalas: una cercana al peatón desde la acera, y otra lejana desde la plaza de Colón y el gran cruce del paseo de la Castellana. Por ello, consta de dos elementos: el friso vertical continuo de color blanco, conformado con mínimas formas que toman presencia por su sombra, que lo hace visible desde puntos lejanos de la plaza; y los apliques oscuros y metálicos colocados entre los huecos de los grandes vidrios. En estos últimos, se espacia el muro como si se tratase de un collage-relieve muy cercano a su experimentación en la serie de las "Cajas vacías». Una propuesta que aplica lo aprendido en el relieve de Irún, pero que está ligado a un estado más avanzado de su investigación escultórica.

\section{Notas}

1. Cf. Gabriel Ruiz Cabrero y Patricia Molins, eds., L'arquitectura i l'art dels anys 50 a Madrid (Barcelona: Fundación La Caixa, 1996); y Sociedad Estatal para la Acción Cultural Exterior, España años 50. Una década de creación (Madrid: Sociedad Estatal para la Acción Cultural Exterior, 2004).

2. Colaboraciones más significativas de Oteiza en la arquitectura española: Basílica de Nuestra Seńora de Aránzazu (Luís Laorga y Francisco Javier Sáenz de Oiza, 1955), Cámara de Comercio de Córdoba (José María García Paredes y Rafael de La-Hoz, 1954), Iglesia del Colegio de los P. Dominicos de Valladolid (Miguel Fisac, 1954), Capilla del Camino de Santiago (Francisco Javier Sáenz de Oiza y Romaní, 1954), Pabellón español para la Exposición Universal de Bruselas 1958 (José Antonio Corrales y Ramón Vázquez Molezún, 1958).

3. T. Badiola ha establecido la relación de Oteiza con el panorama artístico internacional tanto de las primeras vanguardias como con otros artistas internacionales coetáneos e influencias posteriores. Cf. Txomin Badiola, «Oteiza Propósito Experimental», en Oteiza: Propósito experimental, coord. Txomin Badiola (Madrid: Fundación Caja de Pensiones, 1988), 29-63. En el mismo sentido cf. Margit Rowell, «Una modernidad intemporal», en Badiola, Oteiza: Propósito, 15-21; y Margit Rowell, "Sentido del sitio / sentido del espacio: la escultura de Jorge Oteiza», en Oteiza: mitoa eta modernotasuna = mito y modernidad, coords. Txomin Badiola y Margit Rowell (Bilbao: Fundación Museo Guggenheim Bilbao, 2004), 43-49.

4.M. Rowell afirma que "El entorno espacial o genius loci de Oteiza fue sin duda fundamental en la formación de su imaginación como escultor». Rowell, «Sentido del sitio», 47.

5. B. Colomina afirma que «la casa tiene el encanto de experimento. En la escala menos y en situaciones más compactas y de mayor control, es posible la especulación». Beatriz Colomina, prefacio en Sueño de habitar, Blanca Lleó (Barcelona: Fundación Caja de Arquitectos, 1998 ), 6.

6. Las reflexiones de Oteiza sobre la integración de la arquitectura y el arte se enmarcan dentro del ambiente cultural que, desde la Bauhaus, apostaba por un diseño total que sería capaz de generar una transformación social. Sobre el caso español, cf. Paula Barriero López, La abstracción geométrica en España 1957-1969 (Madrid: Consejo Superior de Investigaciones Científicas, 2009), 171-172.

7. El relieve de Jorge Oteiza en la planta baja de su vivienda en Irún no es recogido en la principal publicación sobre este tema, cf. Guillermo Zuaznabar, Jorge Oteiza. Animal fronterizo: Casa-Taller, Irún 1957-58 (Barcelona: Actar, 2001). Tampoco aparece en las catalogaciones de la obra de Oteiza, cf. Soledad Álvarez, Jorge Oteiza: pasión y razón (Alzuza: Fundación Museo Jorge Oteiza, 2003); y Badiola, coord., Oteiza: Propósito. Tampoco se recoge en el reciente cortometraje documental que muestra el estado actual de las casas: Jesús Ma Palacios, La casa vacía (2012), película, 20:30, de «Casa vacía», Jesús Ma Palacios, consultado 5 de octubre, 2013, http://txusmaes.wix.com/casavacia/\#!casa-vacia/c1mf5.

8. Archivo Jorge Oteiza y Archivo Familia Vallet, Fundación Museo Jorge Oteiza, Alzuza, Navarra. Cf. Emma López-Bahut, «Oteiza y lo arquitectónico. De la estatua-masa al espacio urbano (1948-1960)» (Tesis doctoral, Departamento de Proyectos Arquitectónicos y Urbanismo, Escuela Técnica Superior de Arquitectura, Universidade da Coruña, 2013. La documentación hallada (planos, croquis, correspondencia, textos y fotografías) se recoge ordenada, según las fases establecidas en el anexo «Documentación del proceso constructivo de las Casas de Irún». El análisis de este material es desarrollado en el capítulo V.1. «El Proceso Constructivo de las Casas de Irún».

9. Lot. cit.

10. Carta de Néstor Basterrechea y Jorge Oteiza a Luis Vallet, sin fecha aunque aproximadamente correspondería a la primavera de 1956 , cuando Sáenz de Oiza abandona el proyecto. Esta carta no se conserva en la documentación de Luis Vallet. Ha sido reproducida por Jaime Rodríguez Salis, Oteiza en Irún, 1957-1974 (Irún: Alberdania, 2003), 131; y transcrita por Zuaznabar, Jorge Oteiza. Animal fronterizo, 18-9. 
11. Sáenz de Oiza explicaba: «Recuerdo que les propuse (a Oteiza y Romaní) como modelo de iglesia la reproducción del cuadro de la Flagelación de Cristo, de Piero de La Francesca, que yo tenía en casa que, por cierto, era el cuadro más querido de le Corbusier. Esta referencia fue sustituida por una malla espacial -en clara alusión a Mies van der Rohe- como objeto técnico que pudiera calificar la iglesia». Francisco Javier Sáenz de Oiza, «Disertaciones», El croquis 32-33 (abril 1988): 24.

12. Sáenz de Oiza afirmaba que «Yo he coincidido en eso con Le Corbusier, que era el cuadro de «la Flagelación», que es un cuadro que tiene dos escenas superpuestas. ...y todo eso en una atmósfera de columnas y entablamentos, interiores y exteriores, que no saben si están dentro de una casa o fuera de una casa. Es un cuadro emocionante, que yo lo tengo en grande, reproducido en casa, aunque es pequeñito... que no he visto... está en Urbino». Sáenz de Oiza citado por Francisco Javier Sáenz Guerra, Un mito moderno: una capilla en el Camino de Santiago. Sáenz de Oiza, Oteiza y Romani, 1954 (Alzuza: Fundación Museo Jorge Oteiza, 2007), 130-131.

13. Marina y Luis Vallet Montano (nietos de Luis Vallet), en conversación con la autora, Fundación Museo Jorge Oteiza, Alzuza, Navarra, marzo 2006. 14. Fotografías originales de la casa recién construida en las que se aprecia el relieve en la planta baja, en Archivo Museo Jorge Oteiza, ID: 2614, 2475, 2614, 2763, 2811,3833, 6429 y 6430, Fundación Museo Jorge Oteiza, Alzuza, Navarra.

15. Luis Vallet escribía: «Vuestra casa estará cubierta a fin de la semana próxima o quizás antes y pronto empezaremos los cierres de los muros y la distribución interior ¡han salido perfectos los dibujos del techo, el navarrico tenía tantas ganas de verlos que desencofró el techo antes de lo que le habíamos mandado y le obligamos a que apuntalara por lo menos las vigas! Resulta magnífico». Carta de Luis Vallet a Jorge Oteiza, Irún, 15 abril s.f. [aunque es de suponer que de 1957], Archivo Jorge Oteiza, ID: 1647, Fundación Museo Jorge Oteiza, Alzuza, Navarra.

16. Cf. Peio Aguirre y Begoña González, Néstor Basterretxea: forma y universo (Bilbao: Arte Ederren Museoa = Museo de Bellas Artes de Bilbao, 2013).

17. Cf. nota 14 .

18. Cf. nota 8 .

19. Las fotografías de las maquetas del Memorial al p. Donostia en Aguińa (Navarra) que Vallet señala en su carta han sido localizadas en el Archivo Jorge Oteiza, ID: 1550 y 2459, Fundación Museo Jorge Oteiza, Alzuza, Navarra.

20. Señalar que entorno a abril de 1957 Oteiza pone por escrito sus experimentos con la Pared-luz y las reflexiones que le generan en un texto clave: Jorge Oteiza, Propósito experimental 1956-1957 (Madrid: editado por autor, 1957).

21. En Propósito experimental 1956-1957, Oteiza expone su concepto de Muro: «El desarrollo público de una obra depende de las leyes que rigen el espacio anterior al Muro, el cual debe ser calculado y trascendido de manera que el espectador, por primera vez en la historia del Arte, queda incluido activamente en la composición virtual, por la que se reanuda incesantemente el tráfico de las formas, que se orientan en direcciones incurvadas». Oteiza, Propósito experimental, 8.

22. Sobre los trabajos arquitectónicos relacionados con el paisaje natural de Oteiza, véase Emma López Bahut, «Oteiza y la construcción del Paisaje: intervenciones desde la arquitectura en los ańos 50", ZARCH. Journal of interdisciplinary studies in Architecture and Urbanism 1 (2014): (en prensa).

23. Oteiza explicaba: «Espacio es un lugar, un sitio, y este sitio en el que nos desenvolvemos y en el que tratamos de realizar nuestra escultura puede estar ocupado o sin ocupar. Pero este sitio sin ocupar no es vacío. El vacío es la respuesta más difícil y última en el tratamiento y transformación del espacio. El vacío se obtiene, es el resultado de una desocupación espacial, ésta es su energía creada por el escultor, es la presencia de una ausencia formal... En física el vacío se hace, no está. Estéticamente ocurre igual, el vacío es un resultado, resultado de un tratamiento, de una definición del espacio al que ha traspasado su energía una desocupación formal. Un espacio no ocupado no puede confundirse con un espacio vacío...». Jorge Oteiza citado por Rowell, «Sentido del sitio», 25.

24. Jorge Oteiza, «Propósito Experimental Irún», escrito, diciembre 1957, Archivo Jorge Oteiza, ID: 15225, Fundación Museo Jorge Oteiza, Alzuza, Navarra.

25. Loc. Cit.

\section{Procedencia de las ilustraciones}

Fig. 01. Arriba dcha.: Francisco Javier Sáenz de Oiza, Francisco Javier Sáenz de Oiza. Escritos y conversaciones (Barcelona: Fundación Caja de arquitectos, 2006), 134. Arriba izq.: Juan Daniel Fullaondo, coord., Oteiza 1933-68 (Madrid; Barcelona: Nueva Forma; Alfaguara, 1968), 20. Abajo: Néstor Basterrechea y Jorge Oteiza, viviendas para Oteiza y Basterrechea, Irún, sin fecha; croquis del alzado principal y lateral. Fuente: Jaime Rodríguez Salis, Oteiza en Irún, 1957-1974 (Irún: Alberdania, 2003), 131.

Fig. 02. Archivo Familia Luis Vallet, carpeta-11, Fundación Museo Jorge Oteiza, Alzuza (Navarra).

Fig. 03. painttube.files.wordpress.com.

Fig. 04. Archivo Familia Luis Vallet, carpeta-4, Fundación Museo Jorge Oteiza, Alzuza (Navarra).

Fig. 05. Archivo Familia Luis Vallet, carpeta-9, Fundación Museo Jorge Oteiza, Alzuza (Navarra).

Fig. 06. Archivo Jorge Oteiza, ID: 2425, Fundación Museo Jorge Oteiza, Alzuza (Navarra).

Fig. 07. Archivo Jorge Oteiza, ID: 2811, Fundación Museo Jorge Oteiza, Alzuza (Navarra).

Fig. 08. Archivo Familia Luis Vallet, carpeta-3, Fundación Museo Jorge Oteiza, Alzuza (Navarra).

Fig. 09. Archivo Jorge Oteiza, ID: 3833, Fundación Museo Jorge Oteiza, Alzuza (Navarra).

Fig. 10. Archivo Familia Luis Vallet, carpeta-3. Fundación Museo Jorge Oteiza, Alzuza (Navarra).

Fig. 11. Archivo Jorge Oteiza, Fundación Museo Jorge Oteiza, Alzuza (Navarra).

Fig. 12. Txomin Badiola y Margit Rowell, coords., Oteiza: mitoa eta modernotasuna = mito y modernidad (Bilbao: Fundación Museo Guggenheim Bilbao, 2004), 188-189.

Fig. 13. Izq. Dibujos de la autora, 2013. Dcha. Txomin Badiola y Margit Rowell, coords., Oteiza: mitoa eta modernotasuna = mito y modernidad (Bilbao: Fundación Museo Guggenheim Bilbao, 2004), 192, 194-5, 213, 217.

Fig. 14. Dibujos de la autora, 2013.

Fig. 15. Txomin, Badiola, coord., Oteiza: Propósito experimental (Madrid: Fundación Caja de Pensiones, 1988), 210.

\section{Sobre la autora}

Doctora Arquitecta por la Universidade da Coruña (2013). Suficiencia Investigadora por la ETSA de Navarra (2007). Master en Diseño Arquitectónico por la Universidad de Navarra (2004). Arquitecta por la ETSA de Madrid (2002). Ha colaborado profesionalmente con diferentes estudios en Madrid y en Pamplona. Desde 2009, profesora ayudante de proyectos en la ETSA da Coruña. Obtuvo las becas de investigación de la Fundación-Museo Jorge Oteiza entre 2005 y 2007 y del Ministerio de Exteriores MAE-AECID en 2008. Línea de Investigación centrada en las colaboraciones entre la arquitectura y el arte. Pertenece a la Unidad de Investigación pARQc "Proyecto, Arquitectura y Ciudad". Ha realizado ponencias y comunicaciones en diferentes congresos y seminarios, publicando De la escultura a la ciudad. Monumento a Batlle en Montevideo. Oteiza y Puig, 1958-60 (Pamplona, 2007) y colaborado con Francisco Calvo Serraller en la edición crítica del libro de Oteiza Ejercicios Espirituales en un túnel (Pamplona, 2011).

emma.lopez.bahut@gmail.com 